OPEN ACCESS

Edited by:

Carl-Otto Ottosen,

Aarhus University, Denmark

Reviewed by:

Simon Pearson,

University of Lincoln, United Kingdom

Phillip Andrew Davis,

Stockbridge Technology Centre,

United Kingdom

*Correspondence:

Jason Lanoue

jlanoue@uoguelph.ca

Specialty section:

This article was submitted to Crop Science and Horticulture,

a section of the journal

Frontiers in Plant Science

Received: 12 March 2017

Accepted: 06 June 2017

Published: 20 June 2017

Citation:

Lanoue J, Leonardos ED, Ma X and Grodzinski B (2017) The Effect of Spectral Quality on Daily Patterns of Gas Exchange, Biomass Gain, and Water-Use-Efficiency in Tomatoes and Lisianthus: An Assessment of Whole Plant Measurements.

Front. Plant Sci. 8:1076. doi: 10.3389/fpls.2017.01076

\section{The Effect of Spectral Quality on Daily Patterns of Gas Exchange, Biomass Gain, and Water-Use-Efficiency in Tomatoes and Lisianthus: An Assessment of Whole Plant Measurements}

\author{
Jason Lanoue*, Evangelos D. Leonardos, Xiao Ma and Bernard Grodzinski \\ Department of Plant Agriculture, University of Guelph, Guelph, ON, Canada
}

Advancements in light-emitting diode (LED) technology have made them a viable alternative to current lighting systems for both sole and supplemental lighting requirements. Understanding how wavelength specific LED lighting can affect plants is thus an area of great interest. Much research is available on the wavelength specific responses of leaves from multiple crops when exposed to long-term wavelength specific lighting. However, leaf measurements do not always extrapolate linearly to the complexities which are found within a whole plant canopy, namely mutual shading and leaves of different ages. Taken together, both tomato (Solanum lycopersicum) leaves under short-term illumination and lisianthus (Eustoma grandiflorum) and tomato whole plant diurnal patterns of plants acclimated to specific lighting indicate wavelength specific responses of both $\mathrm{H}_{2} \mathrm{O}$ and $\mathrm{CO}_{2}$ gas exchanges involved in the major growth parameters of a plant. Tomato leaves grown under a white light source indicated an increase in transpiration rate and internal $\mathrm{CO}_{2}$ concentration and a subsequent decrease in water-use-efficiency (WUE) when exposed to a blue LED light source compared to a green LED light source. Interestingly, the maximum photosynthetic rate was observed to be similar. Using plants grown under wavelength specific supplemental lighting in a greenhouse, a decrease in whole plant WUE was seen in both crops under both red-blue (RB) and red-white (RW) LEDs when compared to a high pressure sodium (HPS) light. Whole plant WUE was decreased by $31 \%$ under the RB LED treatment for both crops compared to the HPS treatment. Tomato whole plant WUE was decreased by $25 \%$ and lisianthus whole plant WUE was decreased by $15 \%$ when compared to the HPS treatment when grown under RW LED. The understanding of the effects of wavelength specific lighting on both leaf and whole plant gas exchange has significant implications on basic academic research as well as commercial greenhouse production.

Keywords: water-use-efficiency, light-emitting diodes (LED), tomatoes, lisianthus, gas exchange, transpiration, whole plant, greenhouse 


\section{INTRODUCTION}

During the past few decades, technical advancements have made light emitting diodes (LEDs) a viable, new source for both sole and supplemental lighting systems in controlled environments used for basic research purposes, as well as commercial production of fresh produce in greenhouses (Nakamura et al., 1994; Tepperman et al., 2004). Much of what we know about photosynthesis driven by LEDs comes from studies of leaf gas exchange (Goins et al., 1997; Kim et al., 2004a; Hogewoning et al., 2010; Liu et al., 2012).

Leaf measurements have been used as a proxy to understand how the more complex whole plant canopy functions under different environment conditions (Liu et al., 2011a). However, it is well known that leaf metabolism is not a perfect proxy for whole plant metabolism and growth due to metabolic activity of organs/tissues other than leaves, mutual shading, studying leaves of different ages, and differences in canopy architecture including leaf orientation (Davis and McCree, 1978; De Vries, 1982; Dutton et al., 1988). Taken together, the complexities of whole plant photosynthetic and respiratory gas exchange plus canopy architecture do not allow for simple extrapolation of leaf gas exchange kinetics to whole plant metabolic measurements. Whole plant measurements provide the additional data regarding the nature of the plant canopy to be considered. It, therefore, is these gas exchange data collectively that provide a powerful, non-destructive, means of estimating daily growth patterns of the entire plant when subjected to different light, $\mathrm{CO}_{2}$, and temperature conditions (Dutton et al., 1988; Leonardos et al., 2014).

It is well known that plant biomass production increases with the amount of light given to the plant (Evans and Hughes, 1961). Recent improvements in LED technology has led to lower production costs and manufacturing of lighting systems for plant growth (Nakamura et al., 1994; Nelson and Bugbee, 2014; Singh et al., 2015). While conventional high pressure sodium (HPS) lighting have some advantages over LEDs, several characteristics of LEDs allow for the potential optimization of lighting treatments including: (i) ability to provide wavelength specific lighting, (ii) a cool light emitting face, and (iii) potential use as inner canopy lighting (Nakamura et al., 1994; Nelson and Bugbee, 2014). An important aspect of the commercial application of LEDs as supplementary lighting is how plant production can be optimized while the greenhouses are also receiving natural solar radiation at different times of the year (Runkle and Heins, 2001; Kim et al., 2004b; Gomez and Mitchell, 2015; Rabara et al., 2017).

One of the major advantages of LED lighting is the ability to administer wavelength specific lighting. Since the early 1940s, it has been known that the main photosynthetic pigments of a leaf, chlorophyll $a$ and $b$, preferentially absorb certain wavelengths of light (red and blue; Mackinney, 1941). It has been determined that not only are different wavelengths from LED lights absorbed differently, but they are also able to create different plant morphological traits, alter leaf anatomy, cause different stomatal responses, alter flowering time, and even alter gene expression in a variety of plant species (Runkle and Heins, 2001; Tepperman et al., 2004; Liu et al., 2011a,b; Gomez and Mitchell, 2015; Snowden et al., 2016; Rabara et al., 2017).

Advancements in genetic engineering and breeding places an entirely new emphasis on plant phenotyping approaches that should consider and differentiate gas exchanges of the leaf (primary photosynthetic organ) and those of the more complex plant canopy (whole plant organism; Leonardos and Grodzinski, 2016). To our knowledge, current plant literature lacks studies that indicate how the new LED lighting systems might be affecting photosynthetic, respiratory and water exchanges at the whole plant level over the course of a diurnal period, not merely during short-term measurements.

Currently, there is little information dealing with the interrelationships among transpiration, water use, and growth patterns of plants that are being grown under LEDs. What little data on water-use-efficiency (WUE) and growth patterns that are available have come from interpretation of gas exchange at the leaf level. In this study, we provide data showing relationships between light quality produced by different LED fixtures on the diurnal whole plant net carbon exchange rate (NCER), transpiration rate, and WUE of a major vegetable crop, tomato (Solanum lycopersicum) and an ornamental cut flower, lisianthus (Eustoma grandiflorum), both requiring supplemental lighting when these crops are produced in controlled greenhouse environments during winter periods.

\section{MATERIALS AND METHODS Plant Material and Growth Conditions}

Seeds of S. lycopersicum cv. "Bonny Best" (BB) were obtained from William Dam Seeds (Dundas, ON, Canada). Seeds were sown in 60 cavity potting trays in Sungro professional growing mix \#1 (Soba Beach, AB, Canada) between December 2015 and March 2016 and placed in a greenhouse misting bed. Plantlets were then transferred to larger 1L pots containing Sungro growing mix \#1 and these were placed in our research greenhouse at the University of Guelph $\left(43^{\circ} 31^{\prime} 40.0584^{\prime \prime} \mathrm{N}, 80^{\circ}\right.$ $\left.13^{\prime} 38.4996^{\prime \prime} \mathrm{W}\right)$.

E. grandiflorum cv. "Flare" (Lisianthus) rooted plantlets were obtained from John Slamans Greenhouse Ltd., (Burford, ON, Canada). Lisianthus plants were also raised in pots in the same greenhouse in a similar manor as the tomatoes.

Tomato and lisianthus plants were placed under 4 different light treatments, each of which was replicated 3 times in a randomized block design. Light treatments included an ambient (natural light/control), and three supplemental light treatments each providing $100 \pm 25 \mu \mathrm{mol} \mathrm{m} \mathrm{m}^{-2} \mathrm{~s}^{-1}$ of supplemental photosynthetically active radiation (PAR) as determined by a Li-COR quantum sensor (Li-190SA, Li-COR Inc. Lincoln, NE, USA) at pot level at the beginning of the experiment from HPS lights (Agrolite XT; Phillips Lighting, Markham, ON, Canada), red-blue LEDs (LsPro ${ }^{\circledR}$ VividGro ${ }^{\circledR}$ V1 Grow Fixture; Lighting Science Group Company (LSGC) Warwick, RI, USA), and red-white LEDs (LSGC; Figure 1A). Supplementary light was 

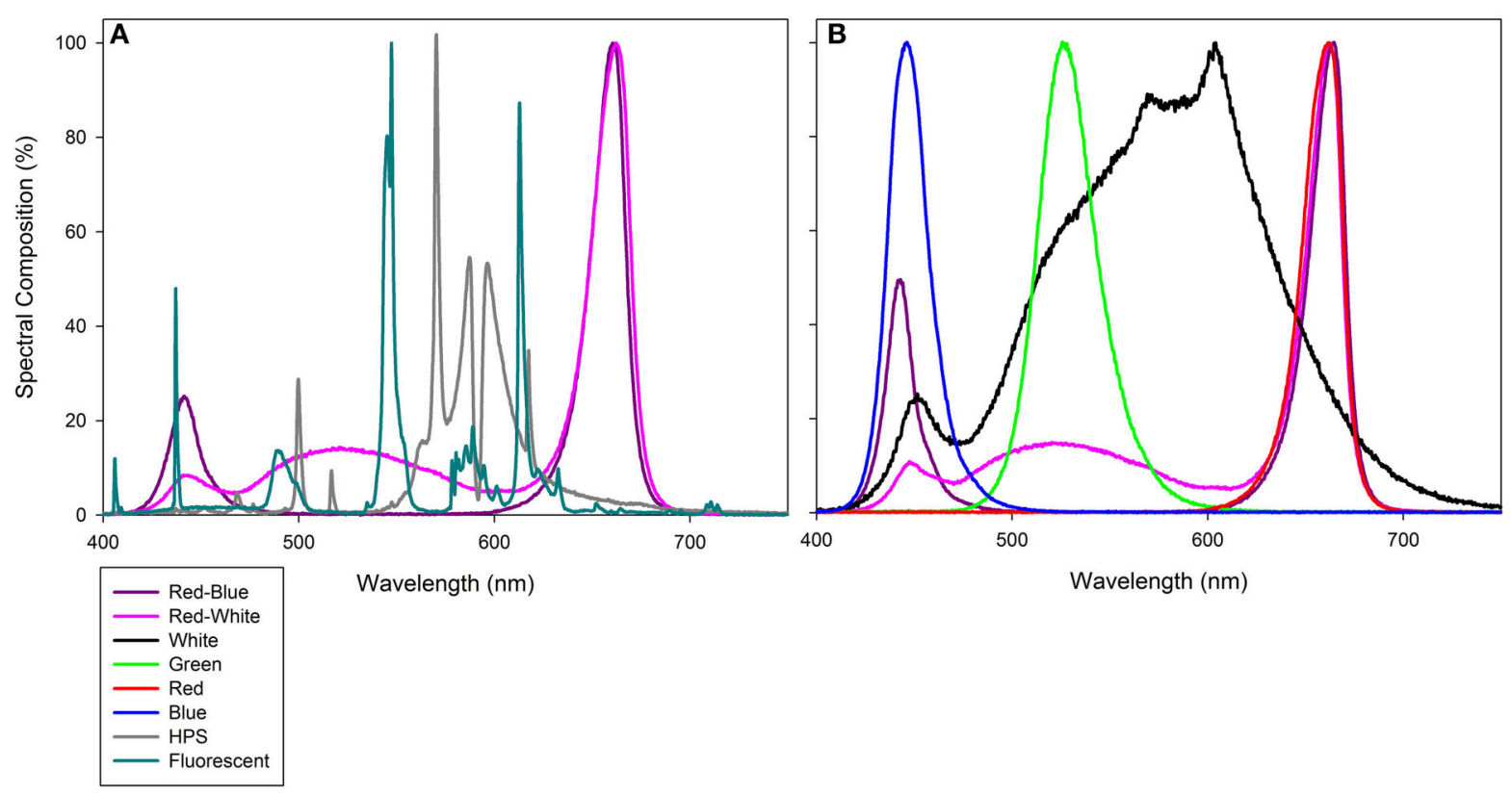

FIGURE 1 | Photosynthetically active radiation (PAR) spectrum of compact fluorescence growth light within the Bio-chambers for plants involved in leaf studies (A), as well as HPS, RB LED, and RW LED from Philips Lighting Company and LSGC, respectively which were used during both greenhouse grow periods and during whole plant analysis. (B) provides the PAR spectrum of PAR 38 LED floodlights from LSGC. All light spectra were determined using a spectroradiometer (Flame Spectrometer, Ocean Optics, Dunedin, FL, USA). Spectral composition (\%) of each light can be found in Supplementary Table 1.

provided for $16 \mathrm{~h}$ daily from 6:00 a.m. to 10:00 p.m. Shade curtains were utilized when solar radiation exceeded $500 \mu \mathrm{mol}$ $\mathrm{m}^{-2} \mathrm{~s}^{-1}$ of PAR. The temperature was maintained at $20^{\circ} \mathrm{C}$ during the day and night period, relative humidity $(\mathrm{RH})$ was maintained around $55 \%$ and plants were watered with fertilizer (20-8-20, Micronutrients; Boron (B) $=200$ ppm, Copper $(\mathrm{Cu})$ $=500 \mathrm{ppm}$, Iron $(\mathrm{Fe})=1000 \mathrm{ppm}$, Manganese $(\mathrm{Mn})=500$ ppm, Molybdenum $(\mathrm{Mo})=150 \mathrm{ppm}$, Zinc $(\mathrm{Zn})=500 \mathrm{ppm}$, Magnesium $(\mathrm{Mg})=1500 \mathrm{ppm} ; \mathrm{pH}=6, \mathrm{EC}=2.3 \mathrm{mS} / \mathrm{cm})$ as needed. Plants grown during this low (natural) light, winter period were used for both whole plant gas exchange studies and destructive biomass analysis.

In addition to growing tomato plants in the greenhouse, populations of $\mathrm{BB}$ tomatoes were also grown from seeds in a growth chamber (GC-20 Bigfoot series, Biochambers, Winnipeg, MB, Canada). Temperature was set to $22 / 18^{\circ} \mathrm{C}$ $(\mathrm{d} / \mathrm{n})$ with a $16 / 8 \mathrm{~h}$ photoperiod. Plants in these growth cabinets were illuminated with $300 \pm 50 \mu \mathrm{mol} \mathrm{m} \mathrm{m}^{-2} \mathrm{~s}^{-1}$ of PAR as determined by a Li-COR quantum sensor at canopy level supplied by compact fluorescence lights (CFL; Sylvania Pentron 841 HO Ecologic, Wilmington, MA, USA; Figure 1A). The $\mathrm{RH}$ was maintained at $60 \pm 10 \%$ and plants were watered with fertilizer (24-8-16; Miracle $\mathrm{Gro}^{\mathrm{TM}}$, Micronutrients; Boron $(\mathrm{B})=200 \mathrm{ppm}$, Copper $(\mathrm{Cu})=700$ ppm, Iron $(\mathrm{Fe})=1500 \mathrm{ppm}$, Manganese $(\mathrm{Mn})=500 \mathrm{ppm}$, Molybdenum $(\mathrm{Mo})=5 \mathrm{ppm}$, Zinc $(\mathrm{Zn})=600 \mathrm{ppm} ; \mathrm{pH}=$ $5.8, \mathrm{EC}=2.6 \mathrm{mS} / \mathrm{cm}$; Marysville, $\mathrm{OH}$, USA) as needed. Plants from these growth cabinets were used for leaf gas exchange measurements.

\section{Growth Analyses of Greenhouse Grown Crops \\ Whole Plant Gas Exchange and Diurnal Growth Patterns}

Our current whole plant gas exchange system which is comprised of six polycarbonate/glass chambers is similar to that described previously (Dutton et al., 1988; Leonardos et al., 2003). Gas exchange measurements were made by sampling each chamber for $90 \mathrm{~s}$, cycling through all chambers every $9 \mathrm{~min}$ throughout the day and night periods over a $36-48 \mathrm{~h}$ period (one run). Two chambers were illuminated with the same HPS lights, two chambers were illuminated with the same red-blue LED luminaries, and the final two chambers were illuminated with the same red-white LED luminaries as above. Light treatments were rotated between the chambers every two runs to remove chamber bias and all chambers were wrapped in aluminum foil to ensure light treatments did not enter an adjacent chamber (Supplementary Figure 1).

For analysis of greenhouse grown tomatoes, experiments started on April 7th, 2016 and continued through April 25th, 2016 [36-54 days after sowing (DAS)]. Plants were placed in the chambers the day before around 3:00pm and measurements used for the calculations were taken from the following day/night period. Lights were set to $500 \pm 10 \mu \mathrm{mol} \mathrm{m}^{-2} \mathrm{~s}^{-1}$ for each light treatment as determined by a Li-COR quantum sensor at the top of the plant and set to a $16 / 8 \mathrm{~h}$ photoperiod. Plants which were grown under supplemental light in the greenhouse (acclimated plants) were analyzed under the same light treatment (i.e., grown under red-blue $\rightarrow$ analyzed under red-blue) and plants which 
were grown under ambient lighting (non-acclimated plants) were analyzed under all supplementary light treatments. Temperature inside the chambers was set to $22 / 18^{\circ} \mathrm{C}$ with a $\mathrm{RH}$ of $55 \pm$ $5 \%$ and $400 \mu \mathrm{L} \mathrm{L}^{-1} \mathrm{CO}_{2}$. The following morning after data collection, plants were removed from the chambers and leaf area was measured using a leaf area meter (Li-COR 3100, Li-COR Inc. Lincoln, NE, USA) and all NCER values were normalized on a leaf basis. Three runs from each block were done amounting in 9 replicates per light treatment.

Analysis involving lisianthus began on March 3rd, 2016 and continued through March 24th, 2016 (120-141 DAS). The same protocol was used as the tomatoes, however conditions were as follows: temperature inside the chambers was set to $22 / 20^{\circ} \mathrm{C}$ with the $\mathrm{RH}$ set to $50 \pm 5 \%$ and a $\mathrm{CO}_{2}$ concentration of $400 \mu \mathrm{L}$ $\mathrm{L}^{-1}$. Again, plants grown under supplemental light were analyzed under the same light they were grown under and ambient plants were analyzed under all 3 supplementary light treatments.

\section{Biomass Partitioning (Destructive Analysis)}

Tomato plants (97 DAS) were destructively analyzed for their end biomass production under their lighting treatments. Two plants from each block (6 plants per light treatment) had their leaf area measured with a leaf area meter and all leaf material (leaves, stems, roots, and flowers) were dried in an oven for $48 \mathrm{~h}$ at $70^{\circ} \mathrm{C}$, allowed to cool for an hour then weighed. An identical protocol was used to determine biomass partitioning within lisianthus (189 DAS). Six plants were taken from each ambient block (18 plants in total) and 4 plants were taken from blocks with supplemental light (12 plants per supplementary light treatment).

\section{Leaf Gas Exchange under Monochromatic and Multicolour LEDs}

Leaf gas exchange begun on chamber grown tomato plants 3135 DAS. The fifth, fully expanded leaf was placed in the chamber of a Li-COR 6400 (Li-COR Inc. Lincoln, NE, USA) which was fitted with a clear top chamber. The leaf temperature within the chamber was held at $22^{\circ} \mathrm{C}$ with a relative humidity of 50 $60 \%$ and $\mathrm{a} \mathrm{CO}_{2}$ level of $400 \mu \mathrm{L} \mathrm{L}^{-1}$. Lights used to generate the leaf gas exchange curves were specially designed LED flood lights (PAR 38, LSGC). The effect of spectral quality on gas exchange was determined using diodes producing the following peak wavelengths: red (R; $660 \mathrm{~nm})$, blue $(B ; 440 \mathrm{~nm})$, orange $(\mathrm{O} ; 595 \mathrm{~nm})$, green $(\mathrm{G} ; 500 \mathrm{~nm})$, white $(\mathrm{W})$, red-blue $(\mathrm{RB})$, or red-white (RW; Figure 1B). Three different leaves, each from a different plant, were used for each light treatment. Light curves began at a high light intensity and decreased incrementally which follows the procedure from Evans and Santiago (2014). At each light level, the photosynthetic rate was allowed to steady, then a $2 \mathrm{~min}$ period was averaged to produce photosynthetic, $\mathrm{C}_{i}$, and transpiration values for that light level. Photosynthetic rates were then plotted against light intensity and a regression line following the equation $\mathrm{f}=\mathrm{y}_{o}+\mathrm{a}\left(1-\mathrm{e}^{\left(-b^{*} x\right)}\right)$ was applied, where $\mathrm{y}_{o}$ is the respiration rate at $0 \mu \mathrm{mol} \mathrm{m} \mathrm{m}^{-2} \mathrm{~s}^{-1}$ of light, a is the maximum Pn rate $\left(\mu \mathrm{mol} \mathrm{m}{ }^{-2} \mathrm{~s}^{-1}\right)$, and $\mathrm{b}$ is the quantum efficiency. The regression line was applied in SigmaPlot to the data points in order to calculate the parameters presented in Table $\mathbf{1}$.

\section{Statistical Analysis}

All statistics were performed used SAS studio 3.5. A one-way ANOVA was performed with a Tukey Kramer adjustment at $p$ $<0.05$ to determine differences between mean values. Outliers were determined by examining internal studentized residuals and comparing them to the Lund's critical value via a Lund's test (Lund, 1975).

\section{RESULTS}

\section{Whole Plant Gas Exchanges}

Figure 2A compares primary whole plant NCER of lisianthus that were grown under only the ambient light conditions in the greenhouse, but were then measured using the three different lighting systems (i.e., HPS, RW LED, and RB LED). In comparison, Figure 2B shows whole plant NCER of lisianthus plants that were grown in the greenhouse under each of the three artificial lighting systems and then measured under these lights. Importantly, the data in Figure 2A, showing nonacclimated plants to the artificial lights, and those in Figure 2B, showing acclimated plants, are very similar and show steady photosynthetic rates during the day. Interestingly, plants which were grown under HPS lighting produced an $\sim 18 \%$ higher whole plant photosynthetic rate throughout the light period than those plants grown under either LEDs (Figure 2B). The difference in whole plant photosynthetic rate under the HPS vs. the two LEDs was only observed when plants were both grown and tested with the HPS lighting and not in plants grown in ambient conditions but exposed to short-term light treatment (Figures 2A,B). A noticeable drop in day-time NCER rates was seen in the RB and RW LED when under acclimated conditions compared to non-acclimated grow conditions (Figures 2A,B). Regardless of the growth conditions (acclimated or nonacclimated plants), all lisianthus plants had a similar NCER at night indicating that respiration patterns were not affected by the type of day time light treatments in these experiments (Figures 2A,B).

Figures 2C,D show the transpiration rates of the same plants that were described in Figures 2A,B, respectively. Under all light conditions, transpiration rates were not steady during either the light or dark periods (Figures 2C,D). In the first half of the photoperiod, transpiration rates increase to a maximum at $14: 00 \mathrm{~h}$ and subsequently declined during the afternoon (Figures 2C,D). When the lights were turned off, there was a dramatic decrease in transpiration rate, consistent with stomatal closure in the dark. However, during the night period, all lisianthus plants showed a gradual increase in their transpiration rates under all conditions (Figures 2C,D). Slightly lower transpiration rates were observed from the acclimated plants under $\mathrm{RB}$ and $\mathrm{RW}$ LED compared to non-acclimated plants (Figures 2C,D). This was not seen in the plants analyzed under HPS plants.

Figures 2E,F show the diurnal patterns of WUE for non-acclimated plants and acclimated plants, respectively, which is a function of both photosynthetic $\mathrm{CO}_{2}$ fixation rates (Figures 2A,B) and water loss through transpiration 


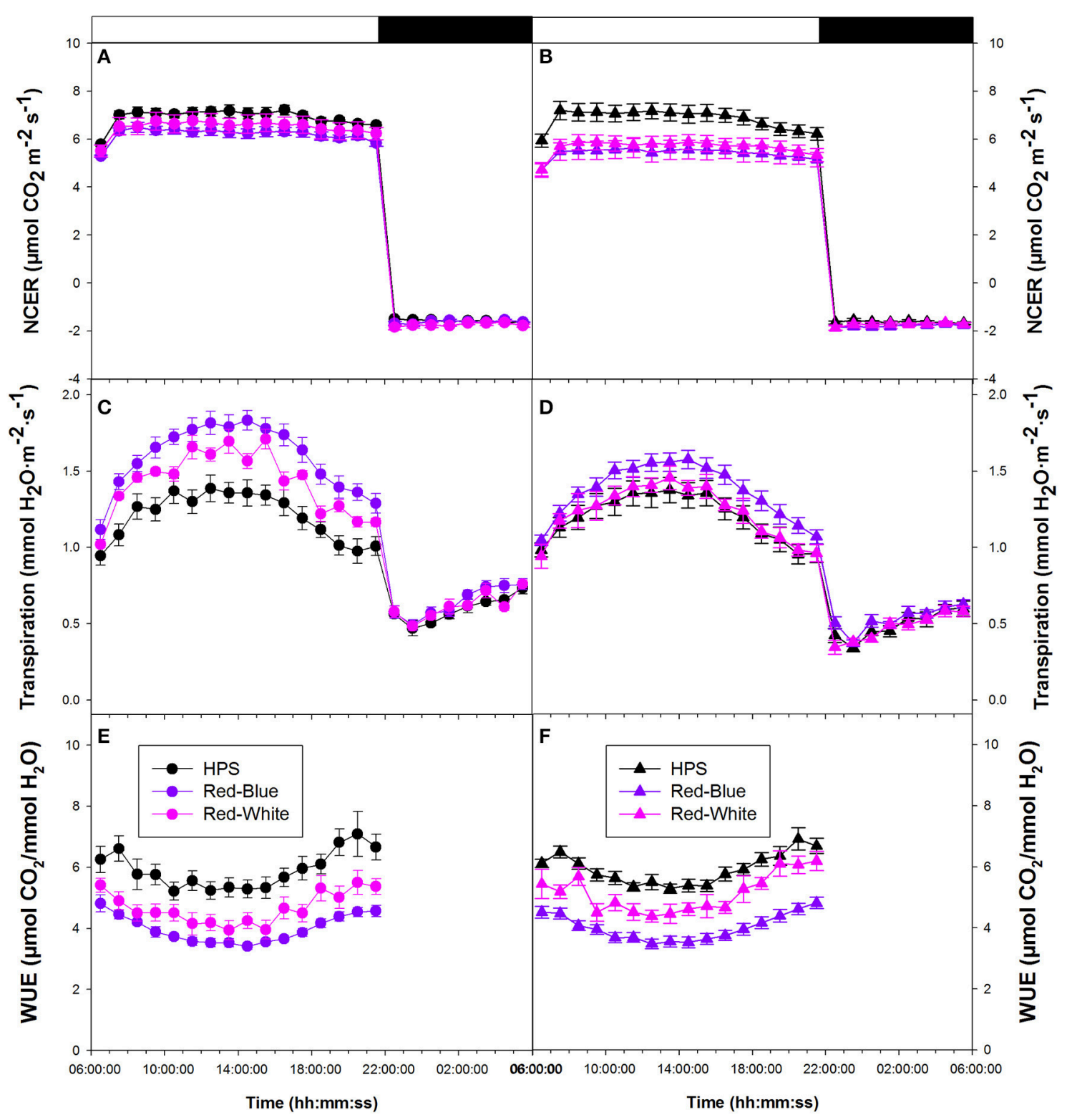

FIGURE 2 | Whole plant diurnal patterns of NCER (A,B), transpiration rate (C,D), and WUE (E,F) of lisianthus plants tested under HPS and RB or RW LED lights, but grown in the greenhouse only under ambient light $(\mathbf{A}, \mathbf{C}, \mathbf{E})$ or with supplemental light $(\mathbf{B}, \mathbf{D}, \mathbf{F})$. Whole plant points represent the hourly mean values \pm the standard error of 12 replicates for panels $(\mathbf{A}, \mathbf{C}, \mathbf{E})$ and 6 replicates for panels (B,D,F).

(Figures 2C,D). Under all light treatments, the non-acclimated plants analyzed under the three different artificial light treatments showed a decrease in WUE during the middle of the photoperiod (Figure 2E). This similar pattern was seen in lisianthus plants which had been acclimated to the three artificial light treatments (Figure 2F). Interestingly, in both nonacclimated and acclimated lisianthus plants, the RB LED light treatment was observed to have the lowest WUE among all light treatments tested (Figures 2E,F).

Figure 3A provides data from tomato plants which were grown in a greenhouse under ambient conditions then subjected to the two LED (RW and RB) and HPS light treatments. Figure 3B shows data which compares plants grown in a greenhouse under supplemental light from either HPS, RW LED, or RB LED. In both experimental conditions, whole plant NCER were seen to be steady throughout both day and night periods (Figures 3A,B). All lighting conditions provided similar rates of both photosynthesis and respiration (Figures 3A,B).

Whole plant transpiration rates seen in Figures 3 C,D are from the same non-acclimated and acclimated tomato plants, respectively, as were used in whole plant NCER analysis. 


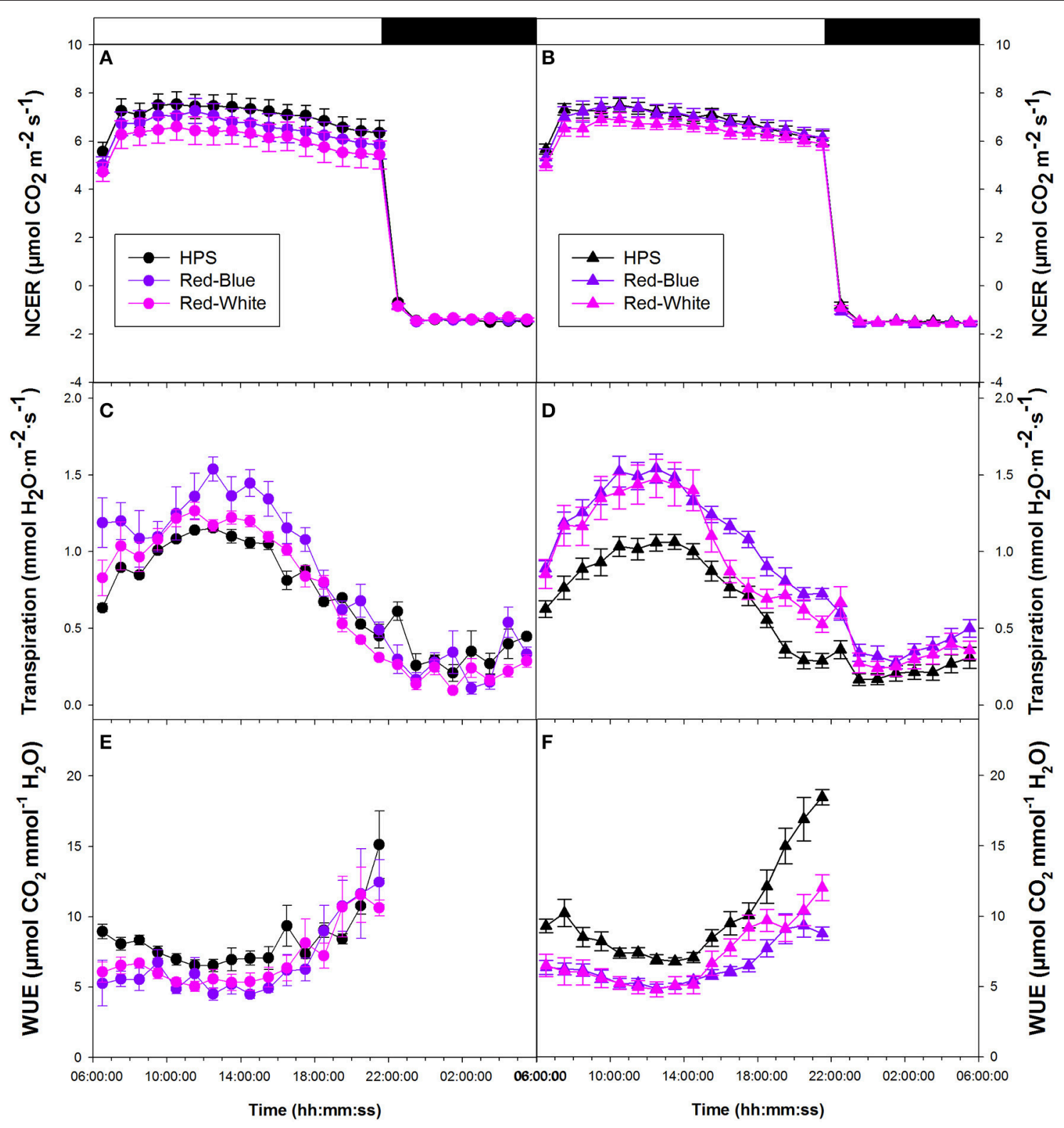

FIGURE 3 | Whole plant diurnal patterns NCER $(\mathbf{A}, \mathbf{B})$, transpiration rate $(\mathbf{C}, \mathbf{D})$, and WUE $(\mathbf{E}, \mathbf{F})$ from greenhouse grown tomato plants under ambient light $(\mathbf{A}, \mathbf{C}, \mathbf{E})$ and supplemental light (B,D,F). Whole plant points represent the hourly mean values \pm the standard error of 9 replicates for both non-acclimated and acclimated plants.

Unlike NCER, transpiration rates increased to a maximum around mid-day and declined thereafter in both non-acclimated and acclimated plants (Figures 3C,D). At the maximum transpiration rate, in both non-acclimated and acclimated plants, plants analyzed under the RB LED light treatment showed an increase of $\sim 50 \%$ from tomato plants analyzed under HPS lighting. Once the lights were turned off $(22: 00 \mathrm{~h})$, there was a subtle increase in transpiration rates during the $8 \mathrm{~h}$ night period (22:00-06:00 h) under all experimental conditions (Figures 3C,D).

Tomato whole plant WUE of non-acclimated plants showed similar patterns under all light treatments (Figure 3E).
Interestingly, there was an increase in WUE from 18:00 to 22:00 h under all light treatments (Figure 3E). Both RW and RB LED light treatments show slightly lower WUE during the morning hours than the HPS light treatment (Figure 3E). Water-use-efficiency of the acclimated plants showed similar patterns to those of non-acclimated tomato plants (Figures 3E,F). At mid-day, WUE values for the RW and RB LED light treatments were $30 \%$ below that of the HPS (Figure 3F). Notably, the HPS treatment showed a very dramatic increase in WUE in the late afternoon compared to that measured with either the RW or the RB LED treatment (Figure 3F). 


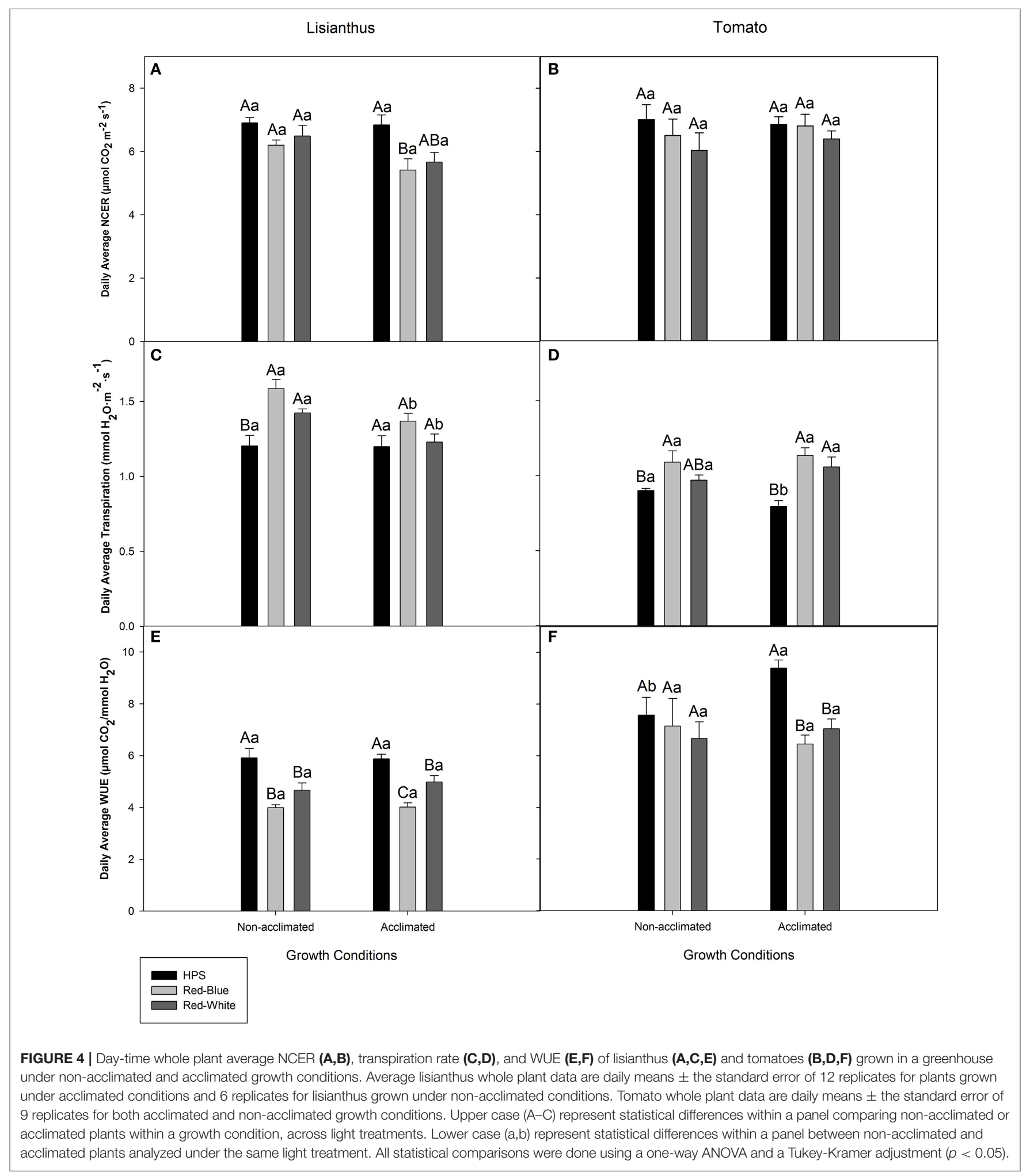

Figure 4 shows the average whole plant photosynthesis, transpiration rate, and WUE during the light period for lisianthus and tomato that were derived from data represented in Figures 2, 3 , respectively. Whole plant photosynthesis for non-acclimated lisianthus grown under ambient light and then subjected to the three light treatments showed no differences (Figure 4A). However, acclimated lisianthus which were grown under HPS light had a higher average photosynthetic rate compared to 

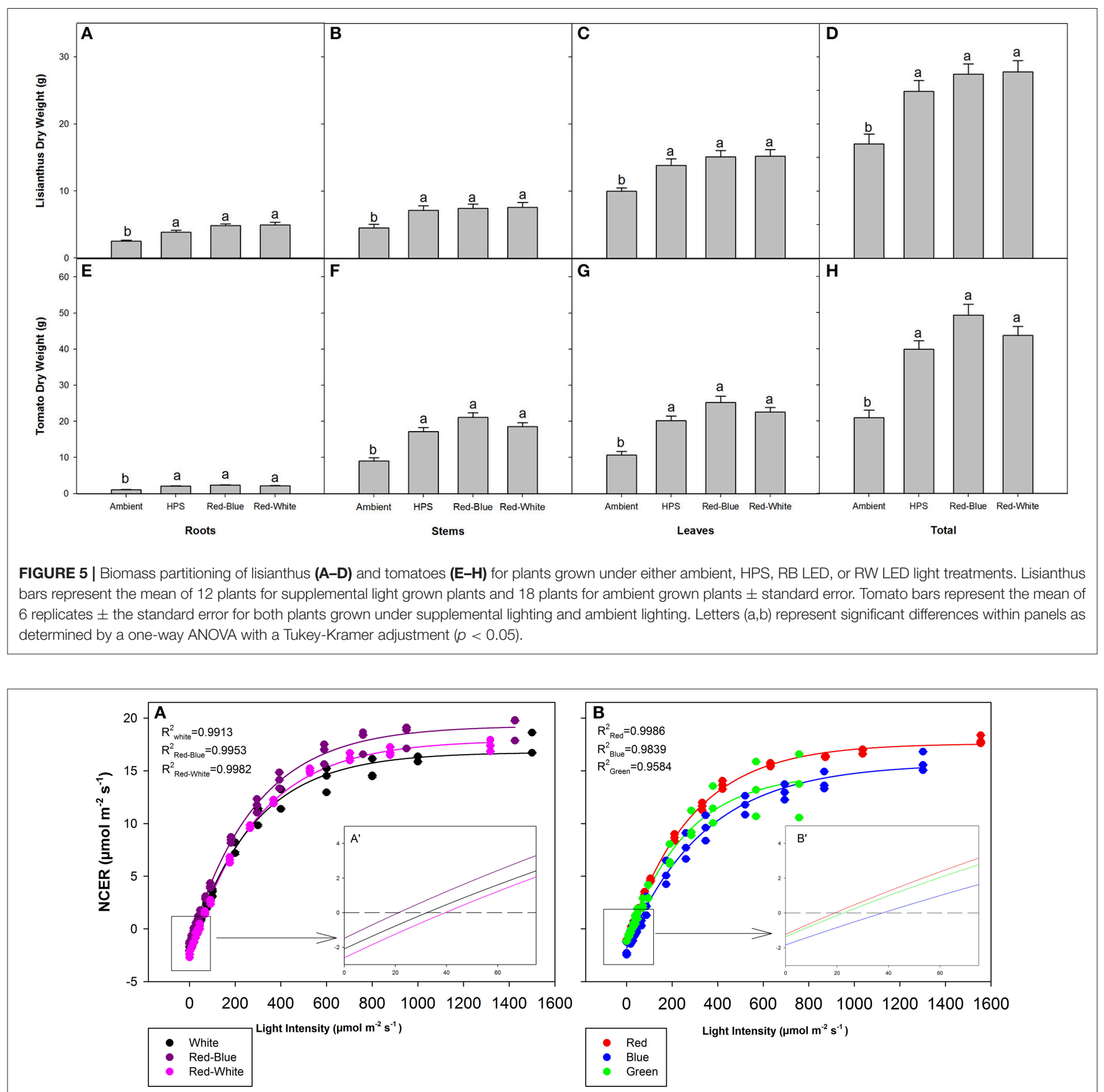

FIGURE 6 | Leaf NCER for mixtures (A) and monochromatic (B) LEDs of tomato plants which were grown in growth chambers under fluorescent light. Insert $A^{\prime}$ and $\mathrm{B}^{\prime}$ are magnifications of the $0-75 \mu \mathrm{mol} \mathrm{m} \mathrm{m}^{-2} \mathrm{~s}^{-1}$ PAR region of panels $(\mathbf{A}, \mathbf{B})$, respectively for better interpretation by the reader. Leaf NCER values of 3 replicate leaves shown with a regression lines fit to $f=y_{0}+a\left(1-e^{\left(-b^{*} x\right)}\right)$ for each light treatment.

the RB LED treatment (Figure 4A). In contrast, the average whole plant photosynthetic rates of the acclimated tomatoes were the same regardless of light treatment (Figure 4B). When comparing non-acclimated vs. acclimated plants of the same species under the same light treatment (i.e., non-acclimated HPS vs. acclimated HPS) no differences in photosynthesis were seen (Figures 4A,B).
The average transpiration rates of non-acclimated lisianthus grown under ambient light then exposed to RW and RB LED were higher than those plants exposed to HPS lighting in the short-term (Figure 4C). No difference was seen in whole plant transpiration rates of acclimated lisianthus plants (Figure 4C). Statistical differences were seen when comparing lisianthus non-acclimated to acclimated plants 

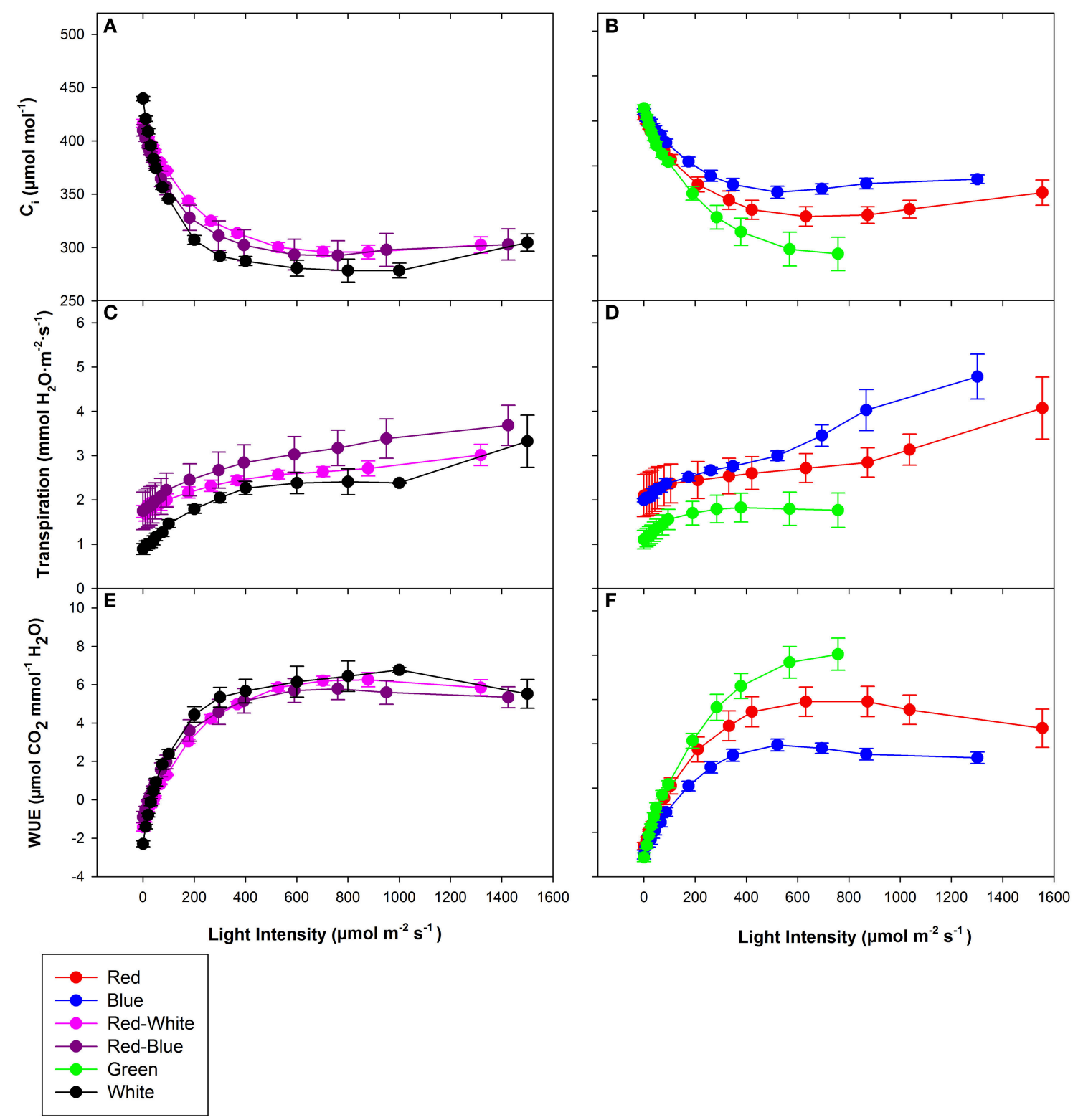

FIGURE 7 | Major physiological traits of a tomato leaf eradiated with LEDs of different spectral quality. Leaf $C_{i} \mathbf{( A , B )}$, leaf transpiration rate $(\mathbf{C}, \mathbf{D})$, and leaf WUE (E,F) of tomato grown in growth chambers under fluorescent light. The data represent data points that each are the mean of 3 different leaves of 3 different plants \pm their respective standard error at that light intensity.

which were analyzed under RB and RW LED light treatments (Figure 4C).

In non-acclimated tomato plants, the RB LED treatments generated a higher transpiration rate than the HPS light treatment (Figure 4D). However, in acclimated tomato plants, those grown and analyzed under both RW and RB LEDs had higher transpiration rates than did plants in the HPS light treatment (Figure 4D). An increase in transpiration rate from tomato plants acclimated under HPS when compared to non-acclimated plants, analyzed under HPS was observed (Figure 4D).
The highest day-time average WUE of both non-acclimated and acclimated lisianthus plants, was observed when analyzed under the HPS light (Figure 4E). Additionally, in acclimated lisianthus plants grown under the RB LED the WUE was lower than that of the RW LED treatment (Figure 4E). No differences were determined between non-acclimated and acclimated lisianthus under any light treatment (Figure 4E).

In non-acclimated tomato plants, no difference in WUE was observed under the different lights (Figure 4F). Notably, with acclimated tomato plants, a decrease in the average WUE of 31 and $25 \%$ was observed under the RB LED and the RW LED, 
TABLE 1 | A summary of the major physiological traits determined by analysis of leaf gas exchanges shown in Figures 6, 7 above.

\begin{tabular}{|c|c|c|c|c|c|c|}
\hline $\begin{array}{l}\text { Light } \\
\text { Treatment }\end{array}$ & $\begin{array}{l}\text { Light compensation } \\
\text { point }\left(\mu \mathrm{mol} \mathrm{m} \mathrm{m}^{-2} \mathrm{~s}^{-1}\right)\end{array}$ & $\begin{array}{l}\text { Quantum } \\
\text { efficiency }\end{array}$ & \multicolumn{4}{|c|}{$\mathrm{Pn}_{\max }$} \\
\hline Red-Blue & $21.40(1.06)^{b}$ & $\begin{array}{l}0.0035(8.8 \times \\
\left.10^{-5}\right)^{\mathrm{a}}\end{array}$ & $20.75(0.71)^{\mathrm{a}}$ & $292.52(13.80)^{\mathrm{ab}}$ & $3.17(0.40)^{\mathrm{ab}}$ & $5.78(0.57)^{\mathrm{ab}}$ \\
\hline Red-White & $40.55(0.72)^{a}$ & $\begin{array}{l}0.0034(5.8 \times \\
\left.10^{-5}\right)^{\mathrm{a}}\end{array}$ & $20.51(0.28)^{a}$ & $296.04(4.70)^{\mathrm{ab}}$ & $2.63(0.11)^{\mathrm{ab}}$ & $6.20(0.23)^{\mathrm{ab}}$ \\
\hline Red & $18.93(0.18)^{b}$ & $\begin{array}{l}0.0035(1.2 \times \\
\left.10^{-4}\right)^{\mathrm{a}}\end{array}$ & $18.80(0.13)^{\mathrm{ab}}$ & $295.44(9.34)^{a b}$ & $2.84(0.33)^{\mathrm{ab}}$ & $5.90(0.68)^{\mathrm{ab}}$ \\
\hline Blue & $37.98(2.47)^{\mathrm{a}}$ & $\begin{array}{l}0.0029(2.0 \times \\
\left.10^{-4}\right)^{\mathrm{a}}\end{array}$ & $17.49(0.05)^{\mathrm{ab}}$ & $324.43(5.86)^{a}$ & $3.45(0.24)^{a}$ & $3.79(0.23)^{b}$ \\
\hline Green & $22.63(2.15)^{\mathrm{ab}}$ & $\begin{array}{l}0.0039(5.0 \times \\
\left.10^{-4}\right)^{\mathrm{a}}\end{array}$ & $16.19(1.98)^{b}$ & $252.23(18.58)^{b}$ & $1.76(0.39)^{b}$ & $8.04(0.72)^{\mathrm{a}}$ \\
\hline
\end{tabular}

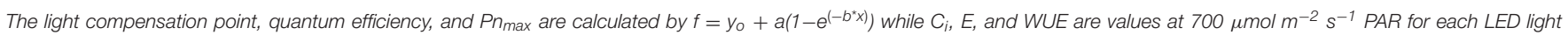

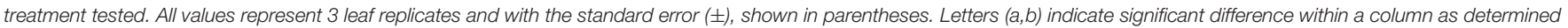
by a one-way ANOVA with a Tukey Kramer adjustment $(p<0.05)$.

respectively, when compared to the WUE of tomatoes grown and analyzed under the HPS lights (Figure 4F). Also, there was a statistical increase in WUE in HPS acclimated tomatoes when compared to non-acclimated tomatoes which were also analyzed under HPS lights (Figure 4F). There was no difference seen between non-acclimated and acclimated tomatoes analyzed under RB or RW LED (Figure 4F).

\section{Biomass Partitioning}

In both lisianthus and tomatoes, plants grown under the three supplemental light treatments produced more total biomass than did the plants grown under the ambient light treatment (Figures 5D,H). Also of note, biomass partitioning was similar when plants were grown under the three different light treatments for both crops, respectively, indicating no preferential biomass accumulation between different sink tissues (Figure 5).

\section{Leaf Gas Exchange under Monochromatic and Multicolour LEDs}

The objective of the tomato leaf studies summarized in Figures 6, 7 as well as Table 1 were primarily to determine if the single major photosynthetic organ on the plant behaved in a manner similar to that of the whole plant canopy with respect to exposure with a wavelength specific LED fixture. Figures 6A, 7A,C,E show leaf responses to the spectra of selected commercially available combinations of LEDs. For ease of representation and visibility, Figures $6 \mathbf{B}, 7 \mathbf{B}, \mathbf{D}, \mathbf{F}$ show the effect of specific wavelength, monochromatic LED fixtures which highlights B, R, and G lights. Taken together, the commercially available combinations of LEDs produced very similar $\mathrm{CO}_{2}$ and $\mathrm{H}_{2} \mathrm{O}$ gas exchange (Figures 6A, 7A,C,E). However, when testing the monochromatic LEDs, the data showed clear differences in all leaf parameters when exposed to $B, R$, and $G$ spectrum of different intensity (Figures 6B, 7B,D,F). Interestingly, even though $\mathrm{CO}_{2}$ gas exchange (Figure 6B) indicate that the $\mathrm{B}$ and G LEDs produced similar NCER values when compared to the $\mathrm{R}$ LED, calculations of $\mathrm{C}_{i}$ (Figure 7B), transpiration rates (Figure 7D), and WUE (Figure 7F) were very different under the $B$ and $G$ LEDs.

The differences shown in Figures 6, 7 are summarized in Table 1. The light compensation points of commercial fixtures indicated a significant difference between the RB and RW LED treatment (Figure 6A' ; Table 1). The light compensation point of $\mathrm{B}$ and $\mathrm{R}$ LED light treatments also produced a difference when comparing the monochromatic LED treatments (Figure 6B'; Table 1). However, both the B and RW treatments produced higher light compensation point than did the $\mathrm{R}$ and RB LED treatments (Table 1). Interestingly, when quantum efficiencies under each of the LEDs were calculated, no difference for the tomato leaves could be observed (Figures 6A,B; Table 1).

When comparing the leaf NCER and WUE of the blended LED mixtures, no differences were noted at any light intensity (Figures 6A,E; Table 1). Figure 6B appears to show a slight difference in NCER rates between the light curves of R compared with $B$ and $G$ LED lights. However, when $\mathrm{Pn}_{\max }$ values were statistically analyzed at $p<0.05$, no difference among any of the monochromatic LED lights was determined (Table 1). However, the RW and RB blended LEDs produced higher $\mathrm{Pn}_{\max }$ than did the $\mathrm{G}$ monochromatic LED treatment (Table 1). The WUE of the G and B LEDs was markedly different (Figure 7F; Table 1). The differences in WUE seemed to be due more to parameters which reflect stomatal functions (Figures 7B,D).

\section{DISCUSSION}

\section{Water-Use-Efficiency of a Leaf under Wavelength Specific LEDs}

Decades of research using filtered white light sources and, more recently, LEDs have determined the photosynthetic response of single leaves of several plants to wavelength specific lighting (McCree, 1972; Goins et al., 1997; Sun et al., 1998; Hogewoning et al., 2010; Liu et al., 2011a). However, most studies have 
used plants which are grown under, or have had long-term acclimatization to the light of interest (Liu et al., 2012; Rabara et al., 2017). Doing so, the possibility that the plants have different morphological characteristics, such as leaf area, stomatal density, and leaf thickness is a major concern (Brazaityte et al., 2010; Liu et al., 2011b, 2012). Thus, if different physical attributes are present at the time measurements are taken, a comparison is not being made between similar leaves/plants. Therefore, the measurements may be a function of long-term exposure to wavelength specific lighting and not a short-term plant response.

Data presented in Figures 6, 7 represents leaves which have been grown under white light and placed under short-term, wavelength specific illumination. This allows for the comparison of similar leaves and how they respond to short-term exposure. The results presented show similar data to those aforementioned studies, indicating that plant responses to wavelength specific lighting is able to happen rapidly (Goins et al., 1997; Hogewoning et al., 2010; Liu et al., 2011a). In all studies it was determined that leaves exposed to a combination of RB light induced the highest photosynthetic response which is what is presented in Figure 6A and Table 1 (Goins et al., 1997; Matsuda et al., 2004; Hogewoning et al., 2010; Liu et al., 2011a). It is also of no surprise that the RW LED treatment produced a high $\mathrm{Pn}_{\max }$ due to the amounts of both R and B light it is comprised of (Liu et al., 2011a).

The $\mathrm{G}$ light treatment produced the lowest $\mathrm{Pn}_{\max }$ among all the light treatments (Table 1). However, at lower light intensities than $\mathrm{Pn}_{\max }, \mathrm{G}$ light was seen to provide a higher photosynthetic rate than did B light (Figure 6B). These findings are in line with results observed in spinach, cabbage, corn, and Miscanthus $\times$ giganteus leaves (Sun et al., 1998, 2012). As expected, the observed photosynthetic responses are highly correlated with the action spectrum of leaves from various species (McCree, 1972). Of note, G light provided a slightly higher quantum efficiency than did the $\mathrm{B}$ light treatment (Table 1). Although this data is calculated using the incident light, it is similar to previous work done with spinach and cabbage leaves (Sun et al., 1998). While B light is known to be highly absorbed by chlorophyll $a$ and $b$, it is also highly absorbed by flavonoids and carotenoids which either do not transfer energy to the reaction center or do so poorly (Sun et al., 1998). Thus, the absorption of B light by other molecules can account for the lower quantum efficiency which was observed (Sun et al., 1998; Table 1).

Photosynthetic rates are not the only parameter effected by wavelength specific lighting. During long-term acclimation to wavelength specific light, stomatal morphology, density, and opening rates have been known to change (Liu et al., 2011a,b; Wang et al., 2016). Current studies analyzing stomatal function are mostly done using leaves which have been under longterm acclimation to wavelength specific light (Liu et al., 2011a, 2012). Internal $\mathrm{CO}_{2}$ concentration $\left(\mathrm{C}_{\mathrm{i}}\right)$, transpiration rates, and WUE values presented in Figure 7 indicated the immediate effect wavelength specific lighting on non-acclimated leaves. A rapid response of stomata when exposed to wavelength specific lighting has also been seen in rice leaves (Qu et al., 2016). At a light level of $700 \mu \mathrm{mol} \mathrm{m} \mathrm{m}^{-2} \mathrm{~s}^{-1}$, B light produced higher transpiration rates and $C_{i}$ values than $G$ light, and subsequently lower WUE (Figure 7; Table 1). Stomatal opening of Xanthium strumarium L., tomato, corn, and $M$. giganteus leaves show similar responses in stomatal function between B and G light (Sharkey and Raschke, 1981; Liu et al., 2012; Sun et al., 2012).

The underlying biochemical mechanism of which $B$ and $G$ light control stomatal functioning has been greatly studied. Blue light has been shown to cause hyperpolarization of guard cells leading to an increase in ion influx, causing stomatal opening (Assmann et al., 1985; Kinoshita and Shimazaki, 1999; Kinoshita et al., 2001; Shimazaki et al., 2007; Zhao et al., 2012). Green light, however, has been shown to have an antagonistic effect on stomatal opening in a variety of plant species (Zeiger and Zhu, 1998; Frechilla et al., 2000; Talbott et al., 2002). The interplay between $B$ and $G$ light effects on stomatal functioning are explanations for the differences in WUE, $C_{i}$, and transpiration rates seen in Figure 7 and Table 1.

\section{Whole Plant, Diurnal Patterns of Biomass Accumulation}

Taken together, both the lisianthus and tomato whole plant diurnal patterns of $\mathrm{CO}_{2}$ and $\mathrm{H}_{2} \mathrm{O}$ exchanges showed that the two LED systems produce significantly lower daily WUE than did the traditional HPS (Figures 2, 3, 4). Although differences in transpiration and WUE were observed, the LEDs and the HPS are comparable in terms of supporting similar biomass gain and the daily carbon budgets (Figures 2, 3).

Plants which were grown under supplemental light produced little or no difference on a whole plant NCER basis, and only lisianthus plants grown under HPS light produced a higher photosynthetic rate (Figure 4B). However, an increase in end biomass production was seen from all of the supplemental light conditions (Figure 5). An increase in biomass production due to the use of supplemental lights has also been seen in cucumber and tomato greenhouse production in various studies (Hao and Papadopoulos, 1999; Dream et al., 2014). Results displayed in Figure 5 for both tomato and lisianthus crops indicate no difference between the different supplemental light treatments used here which is confirmed by the results for tomatoes presented by Dream et al. (2014) and Gomez and Mitchell (2015).

Although no increase was seen, previous literature has shown significant difference between some spectral qualities (Brazaityte et al., 2010; Liu et al., 2012). However, these studies used either a higher light intensity, sole source lighting, or a combination of both (Brazaityte et al., 2010; Liu et al., 2012). Thus, it is likely that at a higher light intensity that plant responses to the different spectral qualities were magnified and an increase in biomass production was able to be seen (Brazaityte et al., 2010; Liu et al., 2012). Also, lights used in these studies provided different spectrums than did the lights which were used in this study (Figure 1; Brazaityte et al., 2010; Liu et al., 2012).

\section{Whole Plant Diurnal Patterns of NCER, Transpiration, and WUE}

Diurnal whole plant NCER showed little to no difference based on spectral quality in tomato or lisianthus (Figures 2, 3, 4). However, differences in both diurnal and daily averages were seen in both transpiration rate and WUE to some extent in 
both species (Figures 2, 3, 4). Thus, illuminating plants with different spectral quality is able to effect transpiration and WUE without major changes to whole plant NCER. These results seem to indicate that spectral quality can have an influence on stomata and their function without affecting the primary photosynthetic machinery. However, it is possible that plants which were grown under supplemental light have altered whole plant and leaf morphologies which has been well documented by others (Gay and Hurd, 1975; Goins et al., 1997; Liu et al., 2011b, 2012; Rabara et al., 2017).

Differences were observed between non-acclimated and acclimated lisianthus and tomato plants in Figures 2, 3, respectively. While it is shown in Figure 5, that these plants have different physical sizes, it is also likely that mutual shading is affecting light interception within the plant. Thus, like the different plant morphologies which are possible between plants growing under different spectra of lights, it is also possible that these differences are due to the inherent difference between plants grown with or without supplemental lighting (Gay and Hurd, 1975; Kumar et al., 2016).

Liu et al. (2011b) have provided evidence indicating the anatomical differences of tomato leaf stomata incurred by light of different spectral qualities. Light treatments which provide high amounts of B light, showed not only increased stomatal aperture but also an increased number of stomata when plants were grown under a $\mathrm{G}, \mathrm{O}$, or dysprosium lamp control (Liu et al., 2011b). Thus, it is possible increased transpiration and decreased WUE from the two LED lights were due to anatomical differences which has been induced by the B component of the lights.

Like tomato leaf studies, the two LED lights which were used in this experiment both contained higher amounts of $\mathrm{R}$ and B light than did the HPS light source (Figure 1A). Thus, it is also possible that stomatal opening is due strictly to the spectral quality they were analyzed under (Iino et al., 1985; Assmann, 1993; Kinoshita et al., 2001). Further, the spectrum of an HPS light is stronger in the $\mathrm{G}$ light region of the visible spectrum than either RB LED, which may further verify studies done by Frechilla et al. (2000) and Talbott et al. (2002).

Of note is the diurnal pattern shown in both transpiration rate and WUE for both species analyzed (Figures 2, 3). In all cases, the stomata which are responsible in part for controlling both of those parameters, seem to follow a defined circadian rhythm under all light treatments only with a translation upwards (transpiration rates) or downwards (WUE) from the LED lights. Plants, like other biological organisms, express circadian rhythms which are able to exist in the absence of light and dark periods (McClung, 2006). Many processes within plants follow a circadian rhythm which include germination, stomatal movement, gas exchange, gene expression and general growth (Cumming and Wagner, 1968; McClung and Kay, 1994).

Within Arabidopsis seedlings, cryptochrome (CRY) proteins show a diurnal pattern reaching maximum expression level a few hours after a light was turned on and subsequently declining there after (Toth et al., 2001). The use of Arabidposis cry 1 cry 2 double mutants displayed a reduced stomatal opening in response to B light which indicates an important role of CRY in stomatal opening (Mao et al., 2005). The diurnal pattern of CRY shown by Toth et al. (2001) follows closely with the transpiration rates shown in Figures 2, 3 and in Dodd et al. (2004) and thus may be a function of CRY involvement in stomatal opening (Mao et al., 2005).

Cryptochrome is a known B light receptor within both plants and animals (Chaves et al., 2011; Christie et al., 2015). Interestingly, the increase in transpiration rate and subsequent decrease in WUE are seen under both the RB and RW LED treatments which contain a higher component of $\mathrm{B}$ light than the HPS light (Figure 1A; Table 1; Supplementary Table 1). With CRY and other B light photoreceptors having a large influence on stomatal opening, the parallel can be drawn that the increase in transpiration rate coupled with the decrease of WUE under the RB and RW treatments is a function of the increased $\mathrm{B}$ light component acting on stomata.

The increase in transpiration rate during the night period which is seen in lisianthus and, to a dampened effect, in tomatoes provides evidence that stomatal functioning is not only monitored by light. Similar results have been reported by Dodd et al. (2004) indicating a rise in transpiration rate during the end of the night period anticipating dawn. Stomatal oscillation patterns presented in Dodd et al. (2004) and Gorton et al. (1989) under continuous light conditions indicate an engrained stomatal circadian rhythm which is not controlled solely by environmental conditions such as light.

During the winter months in greenhouses, not only is light a limiting factor, but humidity is generally lower. This has implications with the way stomata function and causes stomata to be in a more closed state (Lange et al., 1971). Causing stomatal closure will decrease the transpiration rate of the whole plant which can cause imbalances in vital micronutrient uptake which are important in various physiological process (Srivastava and Gupta, 1996; Xu et al., 2000; Baligar et al., 2001; Rouphael and Colla, 2005; Heckman, 2007; Alloway, 2008). The utilization of the RB and RW LEDs can help with the uptake of important nutrients during times of stress due to their ability to control stomatal functioning and increase transpiration rates and thus increase nutrient uptake allowing for proper plant growth.

In summary, understanding the effects of wavelength specific LED lighting on both a leaf and whole plant basis are important. Diurnal patterns of whole plant gas exchanges of $\mathrm{CO}_{2}$ and $\mathrm{H}_{2} \mathrm{O}$ for both tomato and lisianthus indicated clearly an increase in transpiration rates under both RB and RW LED lights compared to HPS lighting and similar photosynthetic and respiratory rates. Although, no differences were seen in NCER or end biomass between those lights, RB and RW LEDs produced statistically lower WUE than did the HPS light. Examination of monochromatic LED lights at the leaf level showed that adjusting $\mathrm{B}, \mathrm{R}$, and $\mathrm{G}$ wavelengths altered $\mathrm{CO}_{2}$ and $\mathrm{H}_{2} \mathrm{O}$ exchanges that accounted for the differences in the WUE patterns that were detected with the large commercially available luminaries. Taken together, both leaf and diurnal whole plant data show the importance in supplemental light selection 
for greenhouse production. In commercial production of both valuable vegetable and cut flower crops, the wavelength of artificial lighting may heavily influences WUE and subsequent nutrient uptake. Little is known about the relationship between WUE, nutrient balance, and spectral quality. The lack of data linking WUE, nutrient balance, and spectral quality have largely been ignored with respect to physiology, breeding studies, and phenology of potential new lines for commercial production.

\section{AUTHOR CONTRIBUTIONS}

All authors listed, have made substantial, direct and intellectual contribution to the work, and approved it for publication.

\section{ACKNOWLEDGMENTS}

This project was supported by National Science and Engineering Research Council, Lighting Science Group Company, Ontario Greenhouse Vegetable Growers, Flowers Canada Group, John Slaman Greenhouse Ltd., and the University of Guelph. We would like to thank Agriculture and Agri-foods Canada (Research Affiliate Program), the University of Guelph (Vitamin Scholarship; Ontario Graduate Scholarship), Ontario government (Ontario Graduate Scholarship), and USDANIFA (Travel grant) for funding provided to JL. We would like to thank Naheed Rana and Jordan Mayfield for valuable technical assistance. Dr. Xiuming Hao (Agriculture and Agri-foods Canada) and Shalin Kholsa (Ontario Ministry of Agriculture, Food and Rural Affairs) for their guidance and recommendations.

\section{REFERENCES}

Alloway, B. J. (ed.). (2008). Micronutrient Deficiencies in Global Crop Production. Springer Science \& Business Media.

Assmann, S. M. (1993). Signal transduction in guard cells. Annu. Rev. Cell Biol. 9, 345-375. doi: 10.1146/annurev.cb.09.110193.002021

Assmann, S. M., Simoncini, L., and Schroeder, J. I. (1985). Blue light activates electrogenic ion pumping in guard cell protoplasts of Vicia faba. Nature 318, 285-287. doi: 10.1038/318285a0

Baligar, V. C., Fageria, N. K., and He, Z. L. (2001). Nutrient use efficiency in plants. Commun. Soil Sci. Plant Anal. 32, 921-950. doi: 10.1081/CSS-100104098

Brazaityte, A., Duchovskis, P., Urbonaviciute, A., Samouliene, G., Jankauskiene, J., Sakalauskaite, J., et al. (2010). The effect of light-emitting diodes lighting on the growth of tomato transplants. Zamdirbyste Agric. 97, 89-98.

Chaves, I., Pokorny, R., Byrdin, M., Hoang, N., Ritz, T., Brettel, K., et al. (2011). The cryptochromes: blue light photoreceptors in plants and animals. Annu. Rev. Plant Biol. 62, 335-364. doi: 10.1146/annurev-arplant-042110-103759

Christie, J. M., Blackwood, L., Petersen, J., and Sullivan, S. (2015). Plant flavoprotein photoreceptors. Plant Cell Physiol. 56, 401-413. doi: $10.1093 /$ pcp/pcu196

Cumming, B. G., and Wagner, E. (1968). Rhythmic processes in plants. Annu. Rev. Plant. Physiol. 19, 381-416. doi: 10.1146/annurev.pp.19.060168.002121

Davis, S. D., and McCree, K. J. (1978). Photosynthetic rate and diffusion conductance as a function of age in leaves of bean plants. Crop Sci. 18, 280-282. doi: 10.2135/cropsci1978.0011183X001800020021x

De Vries, F. W. T. P. (1982). Phases of development of models. Centre of Agricultural Publishing and Documentation (Pudoc), 20-25.

\section{SUPPLEMENTARY MATERIAL}

The Supplementary Material for this article can be found online at: http://journal.frontiersin.org/article/10.3389/fpls.2017. 01076/full\#supplementary-material

Supplementary Figure 1 | Whole plant net carbon exchange system allowing for non-destructive biomass estimation as well as calculation of whole plant photosynthetic, respiration, and transpiration rates. The new modified system employs six, rather than four, polycarbonate/glass chambers similar to those described previously (Dutton et al., 1988; Leonardos et al., 2003). Light was provided from either a HPS, RB LED, or RW LED from Philips Lighting Company and LSGC, respectively. Lights were rotated among the chambers between runs to negate any chamber effects. Each chamber had its own temperature, $\mathrm{CO}_{2}$, humidity, and light sensors allowing for individual control of said chamber. Each chamber is $32^{\prime \prime} \times 18^{\prime \prime} \times 18^{\prime \prime}$ with a total volume of $200 \mathrm{~L}$. The system had two modes of use, an "open" and "closed" mode. In both modes, compressed air generated by the University of Guelph is scrubbed free of $\mathrm{CO}_{2}$ via a purge gas generator $\left(\mathrm{CO}_{2}\right.$ Adsorber, Puregas, Broomfield, $\left.\mathrm{CO}, \mathrm{USA}\right) . \mathrm{CO}_{2}$ was then added back into the system at $400 \mu \mathrm{L} \mathrm{L}^{-1}$. Mixed gas was then pumped to the system via stainless steel piping and series of solenoid valves (ASCO RedHAT II, Florham Park, NJ, USA). $\mathrm{CO}_{2}$ and water measurements were checked every $20 \mathrm{~s}$ in sequential chambers (1 to 6) by infrared gas analyzer (IRGA; Li-COR CO $2 / \mathrm{H}_{2} \mathrm{O}$ gas analyzer 840, Lincoln, NE, USA) in the "open" mode, allowing for adjustment of all chambers. In the "closed" mode, both the inlet and outlet solenoid valves of one chamber were closed allowing for the determination of the depletion of $\mathrm{CO}_{2}$ within said chamber. Sampling took place for $90 \mathrm{~s}$ with the first $30 \mathrm{~s}$ being excluded from calculations via Equation 1.1 where $\mathrm{Vol}$ is the chamber volume $(\mathrm{L})$; $C_{i}$ is the initial $\mathrm{CO}_{2}$ concentration during NCER measurement $\left(\mu \mathrm{L} \mathrm{L}^{-1}\right) ; C_{f}$ is the final $\mathrm{CO}_{2}$ concentration $\left(\mu \mathrm{L} \mathrm{L}^{-1}\right) ; 0.0821$ is the gas constant $\left(\mathrm{L}^{\circ} \mathrm{K}^{-1} \mathrm{~mol}^{-1}\right)$; $\mathrm{T}$ is the temperature $\left({ }^{\circ} \mathrm{K}\right)$ and $\Delta \mathrm{t}$ is the elapse time during sampling (s). After $90 \mathrm{~s}$, the chamber was returned to the "open" mode and the next chamber was then set to the "closed" mode and sampled. One chamber was sample at a time with the other five chambers in the open mode. Sample was done in sequential chambers throughout the entirety of an experiment. NCER $=\frac{v o l\left(c_{j}-C_{f}\right)}{0.0821 * T * \Delta t}$

Supplementary Table 1 | Percentage of blue, green, yellow, orange, and red wavelengths within 714 light spectra provided in Figure 1.

Dodd, A. N., Parkinson, K., and Webb, A. A. R. (2004). Independent circadian regulation of assimilation and stomatal conductance in the $z t l-1$ mutant of Arabidopsis. New Phytol. 164, 63-70. doi: 10.1111/j.1469-8137.2004. 01005.x

Dream, P., Lesfrud, M. G., and Orsat, V. (2014). Supplemental lighting orientation and red-to-blue ratio of light-emitting diodes for greenhouse tomato production. Hortscience 49, 448-452.

Dutton, R. G., Jiao, J., Tsujita, M. J., and Grodzinski, B. (1988). Whole-plant $\mathrm{CO}_{2}$ exchange measurements for non-destructive estimation of growth. Plant Physiol. 86, 355-358. doi: 10.1104/pp.86.2.355

Evans, G. C., and Hughes, A. P. (1961). Plant growth and the aerial environment. New Phytol. 60, 150-180. doi: 10.1111/j.1469-8137.1961.tb06249.x

Evans, J. R., and Santiago, L. S. (2014). PrometheusWiki gold leaf protocol: gas exchange using Li-COR 6400. Funct. Plant Biol. 41, 223-226. doi: 10.1071/FP10900

Frechilla, S., Talbott, L. D., Bogomolni, R. A., and Zeiger, E. (2000). Reversal of blue light-stimulated stomatal opening by green light. Plant Cell Physiol. 41, 171-176. doi: 10.1093/pcp/41.2.171

Gay, A. P., and Hurd, R. G. (1975). The influence of light on stomatal density in the tomato. New Phytol. 75, 37-46. doi: 10.1111/j.1469-8137.1975.tb01368.x

Goins, G. D., Yorio, N. C., Sanwo-Lewandowski, M. M., and Brown, C. S. (1997). Photomorphogenesis, photosynthesis, and seed yield of wheat plants grown under red light-emitting diodes (LEDs) with and without supplemental blue lighting. J. Exp. Bot. 48, 1407-1413. doi: 10.1093/jxb/48.7.1407

Gomez, C., and Mitchell, C. A. (2015). Growth responses of tomato seedling to different spectra of supplemental lighting. Hortscience 50, $112-118$. 
Gorton, H. L., Williams, W. E., Binns, M. E., Gemmell, C. N., Leheny, E. A., and Shepherd, A. C. (1989). Circadian stomatal rhythms in epidermal peels from Vicia faba. Plant Physiol. 90, 1329-1334.

Heckman, J. R. (2007). “Chlorine," in Handbook of Plant Nutrition, eds A. V. Barker and D. J. Pilbeam (Boca Raton, FL: CRC Press), 279-291.

Hao, X., and Papadopoulos, A. P. (1999). Effects of supplemental lighting and cover materials on growth, photosynthesis, biomass partitioning, early yield and quality of greenhouse cucumber. Sci. Hortic. 80, 1-18. doi: 10.1016/S0304-4238(98)00217-9

Hogewoning, S. W., Trouwborst, G., Maljaars, H., Poorter, H., van Ieperen, W., and Harbinson, J. (2010). Blue light dose-responses of leaf photosynthesis, morphology, and chemical composition of Cucumis sativus grown under different combinations of red and blue light. J. Exp. Bot. 61, 3107-3117. doi: $10.1093 /$ jxb/erq132

Iino, M., Ogawa, T., and Zeiger, E. (1985). Kinetic properties of the blue-light response of stomata. Proc. Natl. Acad. Sci. U.S.A. 82, 8019-8023.

Kim, H. H., Goins, G. D., Wheeler, R. M., and Sager, J. C. (2004a). Stomatal conductance of lettuce grown under or exposed to different light qualities. Ann. Bot. 94, 691-697. doi: 10.1093/aob/mch192

Kim, H. H., Goins, G. D., Wheeler, R. M., and Sager, J. C. (2004b). Greenlight supplementation for enhanced lettuce growth under red- and blue-lightemitting diodes. Hortscience 39, 1617-1622. doi: 10.1093/aob/mch192

Kinoshita, T., Doi, M., Suetsugu, N., Kagawa, T., Wada, M., and Shimazak, K. (2001). Phot1 and phot2 mediate blue light regulation of stomatal opening. Nature 414, 656-660. doi: 10.1038/414656a

Kinoshita, T., and Shimazaki, K. (1999). Blue light activates the plasma membrane $\mathrm{H}^{+}$-ATPase by phosphorylation of the C-terminus in stomatal guard cells. EMBO J. 18, 5548-5558. doi: 10.1093/emboj/18.20.5548

Kumar, K. G. S., Hao, X., Khosla, S., Guo, X., and Bennett, N. (2016). Comparison of HPS lighting and hybrid lighting with top HPS and intra-canopy LED lighting for high-wire mini-cucumber production. Acta Hortic. 1134, 111-118. doi: 10.17660/ActaHortic.2016.1134.15

Lange, O. J., Losch, R., Schulze, E. D., and Kappen, L. (1971). Responses of stomata to changes in humidity. Planta 100, 76-86. doi: 10.1007/BF00386887

Leonardos, E. D., and Grodzinski, B. (2016). "Quantifying growth nondestructively using whole-plant $\mathrm{CO}_{2}$ exchange is a powerful tool for phenotyping," in Handbook of Photosynthesis, 3rd Edn., ed M. Pessarakli (Boca Raton, FL: CRC Press), 571-589.

Leonardos, E. D., Rauf, S. A., Weraduwage, S. M., Marillia, E. F., Taylor, D. C., Micallef, B. J., et al. (2014). Photosynthetic capacity of the inflorescence is a major contributor to daily-C-gain and the responsiveness of growth to elevated $\mathrm{CO}_{2}$ in Arabidopsis thaliana with repressed expression of mitochondrial-pyruvate-dehydrogenase-kinase. Environ. Exp. Bot. 107, 84-97. doi: 10.1016/j.envexpbot.2014.05.007

Leonardos, E. D., Savitch, L. V., Huner, N. P. A., Oquist, G., and Grodzinski, B. (2003). Daily photosynthetic and C-export patterns in winter wheat leaves during cold stress and acclimation. Physiol. Plant 117, 521-531. doi: 10.1034/j.1399-3054.2003.00057.X

Liu, X. Y., Chang, T. T., Guo, S. R., Xu, Z. G., and Li, J. (2011a). Effect of different light quality of LED on growth and photosynthetic character in cherry tomato seedlings. Acta. Hortic. 907, 325-330. doi: 10.17660/ActaHortic.2011.907.53

Liu, X. Y., Gou, S. R., Xu, Z. G., Jiao, X. L., and Tezuka, T. (2011b). Regulation of chloroplast ultrastructure, cross-section anatomy of leaves, and morphology of stomata of cherry tomato by different light irradiations of light-emitting diodes. Hortscience 46, 217-221.

Liu, X. Y., Guo, S. R., Chang, T. T., Xu, Z., and Tezuka, T. (2012). Regulation of the growth and photosynthesis of cherry tomato seedlings by different light irradiations of light emitting diodes (LED). Afr. J. Biotechnol. 11, 6169-6177. doi: $10.5897 /$ AJB11.1191

Lund, R. E. (1975). Tables for an approximate test for outliers in linear models. Technometics 17, 473-476. doi: 10.1080/00401706.1975.10489374

Mackinney, G. (1941). Absorption of light by chlorophyll solutions. J. Biol. Chem. 140, 315-322.

Mao, J., Zhang, Y. C., Sang, Y., Li, Q. H., and Yang, H. Q. (2005). A role of Arabidposis cryptochromes and COP1 in the regulation of stomatal opening. Proc. Natl. Acad. Sci. 102, 12270-12275. doi: 10.1073/pnas.0501011102

Matsuda, R., Ohashi-Kaneko, K., Fujiwara, K., Goto, E., and Kurata, K. (2004). Photosynthetic characteristics of rice leaves grown under red light with or without supplemental blue light. Plant Cell Physiol. 45, 1870-1874. doi: $10.1093 / \mathrm{pcp} / \mathrm{pch} 203$

McClung, R. J. (2006). Plant circadian rhythms. Plant Cell 18, 792-803. doi: 10.1105/tpc.106.040980

McClung, R. J., and Kay, S. A. (1994). "Circadian rhythms in Arabidopsis thaliana," in Arabidopsis, eds E. M. Meyerowitz and, C. R.Somerville (Cold Spring Harbour, NY: Cold Spring Harbor Laboratory Press), 615-637.

McCree, K. J. (1972). The action spectrum, absoprtance and quantum yield of photosynthesis in crop plants. Agric. Meterol. 9, 191-216. doi: 10.1016/0002-1571(71)90022-7

Nakamura, S., Mukai, T., and Senoh, M. (1994). Candela-class high-brightness InGaN/AlGaN double-heterostructure blue-light-emitting diodes. Appl. Phys. Lett. 64, 1687-1689. doi: 10.1063/1.111832

Nelson, J. A., and Bugbee, B. (2014). Economic analysis of greenhouse lighting: light emitting diodes vs. High intensity discharge fixtures. PLoS ONE 9:e99010. doi: 10.1371/journal.pone.0099010

Qu, M., Hamdani, S., Li, W., Wang, S., Tang, J., Chen, Z., et al. (2016). Rapid stomatal response to fluctuating light: an under-explored mechanism to improve drought tolerance in rice. Funct. Plant Biol. 43, 727-738. doi: 10.1071/FP15348

Rabara, R. C., Behrman, G., Timbol, T., and Rushton, P. J. (2017). Effects of spectral quality of monochromatic LED lights on the growth of artichoke seedlings. Front. Plant Sci. 8:190. doi: 10.3389/fpls.2017. 00190

Rouphael, Y., and Colla, G. (2005). Growth, yield, fruit quality and nutrient uptake of hydrophonically cultivated zucchini squash as affected by irrigation systems and growing seasons. Sci. Hortic. 105, 177-195. doi: 10.1016/j.scienta.2005.01.025

Runkle, E. S., and Heins, R. D. (2001). Specific functions of red, far red, and blue light in flowering and stem extension of long-day plants. J. Am. Soc. Hort. Sci. $126,275-282$.

Sharkey, T. D., and Raschke, K. (1981). Effect of light quality on stomatal opening in leaves of Xanthium strumarium L. Plant Physiol. 68, 1170-1174. doi: 10.1104/pp.68.5.1170

Shimazaki, K., Doi, M., Assmann, S. M., and Kinoshita, T. (2007). Light regulation of stomatal movement. Annu. Rev. Plant Biol. 58, 219-247. doi: 10.1146/annurev.arplant.57.032905.105434

Singh, D., Basu, C., Meinhardt-Wollweber, M., and Roth, B. (2015). LEDs for energy efficient greenhouse lighting. Renew. Sustain. Ener. Rev. 49, 139-147. doi: 10.1016/j.rser.2015.04.117

Snowden, C. M., Cope, K. R., and Bugbee, B. (2016). Sensitivity of seven diverse species to blue and green light: integrations with photon flux. PLoS ONE 11:e0163121 doi: 10.1371/journal.pone.0163121

Srivastava, P. C., and Gupta, U. C. (1996). Trace Elements in Crop Nutrition. Lebanon, NH: Science Publishers.

Sun, J., Nishio, J. N., and Vogelmann, T. C. (1998). Green light drives $\mathrm{CO}_{2}$ fixation deep within leaves. Plant Cell Physiol. 39, 1020-1026. doi: 10.1093/oxfordjournals.pcp.a029298

Sun, W., Ubierna, N., Ma, J. Y., and Cousins, A. B. (2012). The influence of light quality on $\mathrm{C}_{4}$ photosynthesis under steady-state conditions in Zea mays and Miscanthus x giganteus: changes in rates of photosynthesis but no the efficiency of the $\mathrm{CO}_{2}$ concentrating mechanism. Plant Cell Environ. 35, 982-993. doi: 10.1111/j.1365-3040.2011. 02466.x

Talbott, L. D., Nikolova, G., Ortiza, A., Shmayevich, I., and Zeiger, E. (2002). Green light reversal of blue-light-stimulated stomatal opening is found in a diversity of plant species. Am. J. Bot. 89, 366-368. doi: 10.3732/ajb.89.2.366

Tepperman, J. M., Hudson, M. E., Khanna, R., Zhu, T., Chang, S. H., Wang, X., et al. (2004). Expression profiling of phyB mutant demonstrates substantial contribution of other phytochromes to redlight-regulated gene expression during de-etiolation. Plant J. 38, 725-739. doi: 10.1111/j.1365-313X.2004.02084.x

Toth, R., Kevei, E., Hall, A., Millar, A. J., Nagy, F., and Kozma-Bognar, L. (2001). Circadian clock-regulated expression of phytochrome and cryptochrome genes in Arabidopsis. Plant Physiol. 127, 1607-1616. doi: 10.1104/pp.010467

Wang, J., Lu, W., Tong, Y., and Yang, Q. (2016). Leaf Morphology, photosynthetic performance, chlorophyll fluorescence, stomatal development of lettuce 
(Lactuca sativa L.) exposed to different ratios of red light to blue light. Front. Plant Sci. 7:250. doi: 10.3389/fpls.2016.00250

Xu, G., Magen, H., Tarchitzky, J., and Kafkaf, U. (2000). Advances in chloride nutrition of plants. Adv. Agron. 28, 97-150. doi: 10.1016/S0065-2113(08) 60844-5

Zeiger, E., and Zhu, J. X. (1998). Role of zeaxanthin in blue light photoreception and the modulation of light- $\mathrm{CO}_{2}$ interactions in guard cells. J. Exp. Bot. 49, 433-442. doi: 10.1093/jxb/49.Special_Issue.433

Zhao, X., Qiao, X., Yuan, J., Ma, X., and Zhang, X. (2012). Nitric oxide inhibits blue light-induced stomatal opening by regulating the $\mathrm{K}^{+}$influx in guard cells. Plant Sci. 184, 29-23. doi: 10.1016/j.plantsci.2011.12.007
Conflict of Interest Statement: The authors declare that the research was conducted in the absence of any commercial or financial relationships that could be construed as a potential conflict of interest.

Copyright $\odot 2017$ Lanoue, Leonardos, Ma and Grodzinski. This is an open-access article distributed under the terms of the Creative Commons Attribution License (CC BY). The use, distribution or reproduction in other forums is permitted, provided the original author(s) or licensor are credited and that the original publication in this journal is cited, in accordance with accepted academic practice. No use, distribution or reproduction is permitted which does not comply with these terms. 